\title{
Flight testing of parachute recovery systems aboard REXUS
}

\author{
E. Menting, L. Pepermans, T. Britting, E. Soliman, J. Klaassen, M. Rozemeijer, J. van 't Hof \\ Delft Aerospace Rocket Engineering (DARE) \\ The Netherlands \\ SPEAR@dare.tudelft.nl
}

\begin{abstract}
The Supersonic Parachute Experiment Aboard REXUS or SPEAR mission is a mission by the Parachute Research Group (PRG) of Delft Aerospace Rocket Engineering (DARE). The primary objective is to test the in-house developed Hemisflo ribbon drogue parachute at supersonic conditions. To achieve this a test vehicle is placed in the nose cone of the REXUS sounding rocket and released near apogee $(75-85 \mathrm{~km})$. From apogee, the test vehicle shall follow a ballistic trajectory and deploy the drogue parachute above Mach 1.5.

Besides testing the drogue parachute at supersonic velocities, the secondary goal of the mission is to gather a full validation data set for the DARE ParSim and TumSim simulation tools.

The test vehicle is aerodynamically stabilized and centred around the drogue parachute deployment system. The parachute system is completed by two main parachutes for a safe landing. Data on the parachute performance is stored onboard. All mission critical data, including video, is sent down via telemetry.

The paper describes the SPEAR project, design and testing envelope. Furthermore, an outlook is provided on diverse experiment possibilities for parachute testing on the REXUS sounding rocket.
\end{abstract}

Keywords- Hemisflo ribbon parachute, drogue parachute, supersonic, SPEAR, REXUS, test flight.

\section{INTRODUCTION}

Within Delft Aerospace Rocket Engineering (DARE), the large envelope advanced parachute system (LEAPS) is used as the recovery systems of multiple flagship projects such as Aether, Stratos III and Stratos IV [1]. The Hemisflo ribbon parachute is chosen as the drogue parachute for this system due to its high supersonic capabilities as it can theoretically function up to Mach 3.

When looking at a parachutes deployment and flight, the two most critical parameters are the dynamic pressure and the velocity regimes encountered. The Parachute Research Group (PRG) is able to test the parachutes extensively with wind velocities up to $30 \mathrm{~m} / \mathrm{s}$ and dynamic pressures up to $0.5 \mathrm{kPa}$ in the Open Jet Facility (OJF) at the TU Delft. In these tests the drag and subsonic stability performance of the parachutes can be determined. These conditions however, are not comparable to the deployment conditions of the parachute in flight.

The team has designed a test vehicle, as part of the Parachute Investigation Project (PIP), to test parachutes at dynamic pressures up to $7 \mathrm{kPa}$. This is comparable to the main and drogue parachute deployment conditions in larger DARE missions.

It is however more difficult to test the supersonic capabilities of parachutes. Large size supersonic wind tunnels exist, but are very expensive [2]. Aside costs there is a difference in drag and stability behaviour between parachute performance in a wind tunnel (infinite mass scenario) or in flight (finite mass scenario) [3]. Therefore, a supersonic flight test would be preferred to validate the supersonic performance of this parachute.

Inspired by SuperMAX, flown on MAXUS-9 [2], PRG looked into a sounding rocket piggyback mission for testing the LEAPS drogue parachute. This led to the proposition of a new DARE mission that was to fly on the REXUS sounding rocket as part of the REXUS/BEXUS project; the Supersonic Parachute Experiment Aboard REXUS (SPEAR).

This paper gives an overview of the mission and the measurements to be performed. Furthermore, it gives an overview of the electronic and mechanical design of the experiment, and an outlook on future flight testing of parachutes.

\section{Measurements}

As the SPEAR mission aims to flight test the Hemisflo parachute at supersonic conditions, it is essential to obtain sufficient data in order to reach a post-flight conclusion on the parachute performance.

The data set gathered will include force data from parachute inflation which will be used to validate the "small parachute, supersonic conditions" inflation models in ParSim. Three load cells are used to ensure the parachute inflation load can be measured, even when the parachute force does not act in line with the longitudinal axis of the test vehicle.

Next to this, the inflation behaviour and stability of the parachute will be observed with an HD, high speed camera which is mounted in an upward looking configuration towards the parachutes.

The final onboard sensor to study the drogue parachute is the inertial measurement unit (IMU). This sensor will measure the acceleration in three axes as well as rotational rates.

The inflation of the parachutes can be directly observed from the video images of the on-board camera. The loading conditions during parachute inflation and flight will be obtained during post processing of the load cells and IMU measurements.

Next to parachute related measurements, more data will be gathered from the SPEAR flight in order to validate other assumptions and simulation programs within DARE.

Because SPEAR is expected to experience aerothermal heating effects during re-entry, the heat fluxes will be 
measured to validate the thermal models currently implemented in ParSim. Finally, a camera is mounted on the REXUS rocket in order to confirm that the separation of the vehicle occurred without any issues and a pressure sensor is used for main parachute deployment.

\section{FLIGHT SIMULATIONS}

The SPEAR trajectory consists of four major flight phases, these can be seen in Figure 1. In the first phase, ascent, SPEAR is attached to REXUS. The test vehicle will be separated shortly before apogee.

After this SPEAR and the REXUS rocket will go their separate ways. From around $60 \mathrm{~km}$, SPEAR will undergo a re-entry phase. During this second phase, SPEAR is stabilized by a ballute stabilizer, which ensures the vehicle remains close to a zero-degree angle of attack. This is needed to increase the terminal velocity of the vehicle at drogue parachute inflation. Furthermore, as ParSim assumes a constant angle of attack [5], it is preferred to keep the vehicle as stable as possible.

After re-entry, the vehicle enters the third phases of its descent. In this phase the Hemisflo parachute will be deployed, at supersonic conditions over Mach 1.5. This will be at approximately $25 \mathrm{~km}$ and is dependent on the conditions at the launch site, the performance of the REXUS rocket and the final parameters of the SPEAR vehicle. The team also performs a sensitivity analysis on the velocity at drogue deployment to ensure this requirement is met [4]. Figure 2 Shows the minimum deployment altitude as a function of the apogee altitude and vehicle mass of SPEAR.

When SPEAR reaches an altitude of about $1 \mathrm{~km}$, the main parachutes are deployed to ensure it lands safely with a landing velocity lower than $10 \mathrm{~m} / \mathrm{s}$.

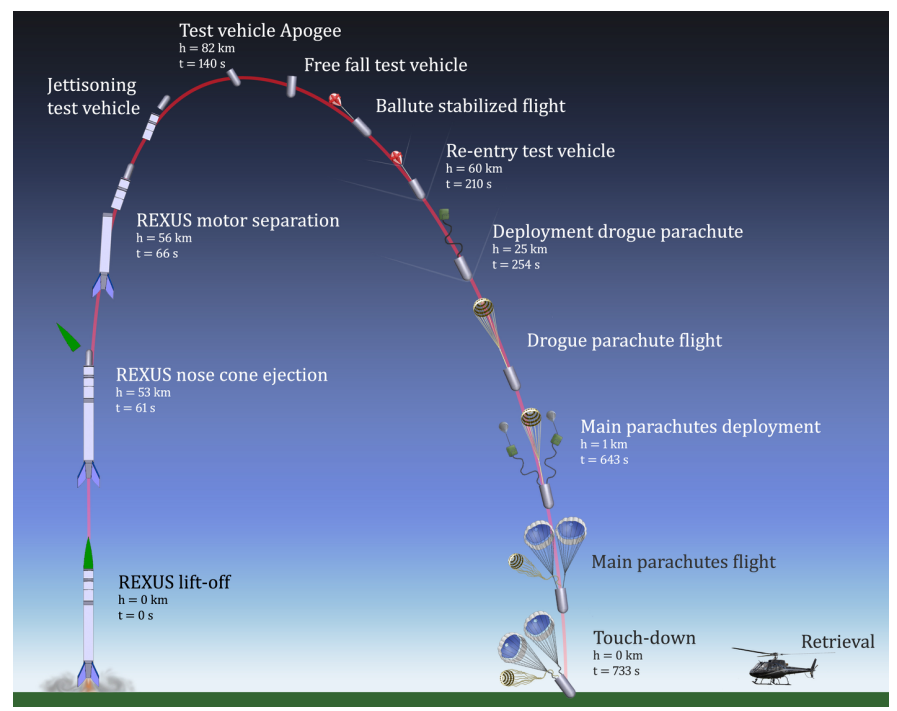

Figure 1 Flight Sequence of the SPEAR mission

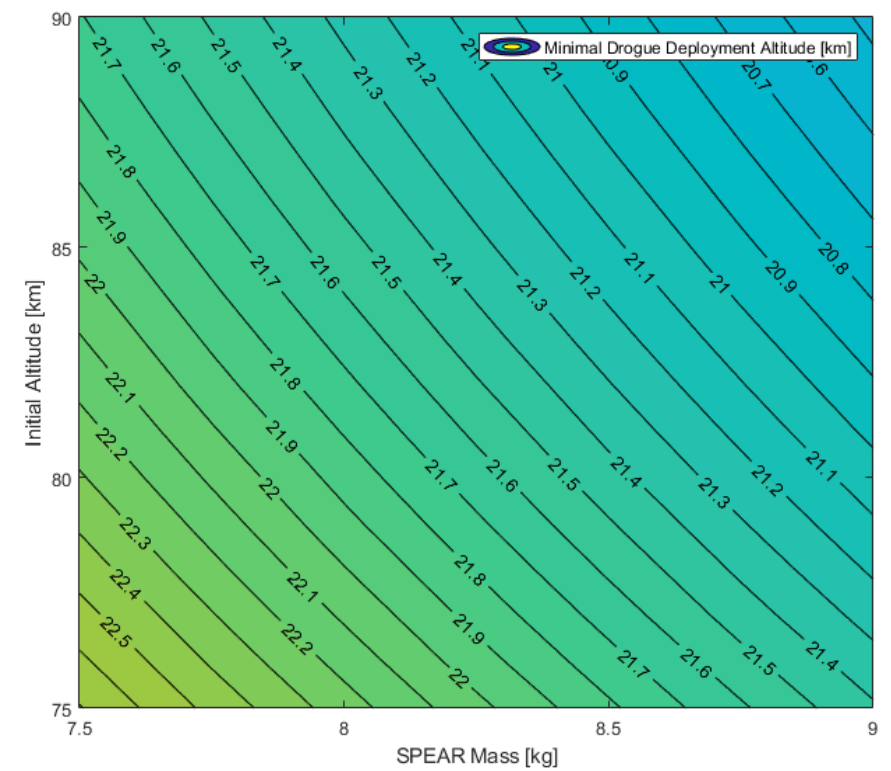

Figure 2 The cross-over point for SPEAR deployment at $M=1.5$

Other than the deployment, the expected forces from the parachute on the vehicle as well as the decelerations during the flight are essential for designing the test vehicle. The constraints lead to the flight envelope of the vehicle which can be seen in Figure 3. Here the maximum parachute inflation loads as well as the maximum dynamic pressure the parachute can handle are plotted in one figure. The envelope shows that the limiting factor in this mission is not the drogue parachute but the main parachutes. This can be seen as the main parachute inflation occurs on the edge of the flight envelope.

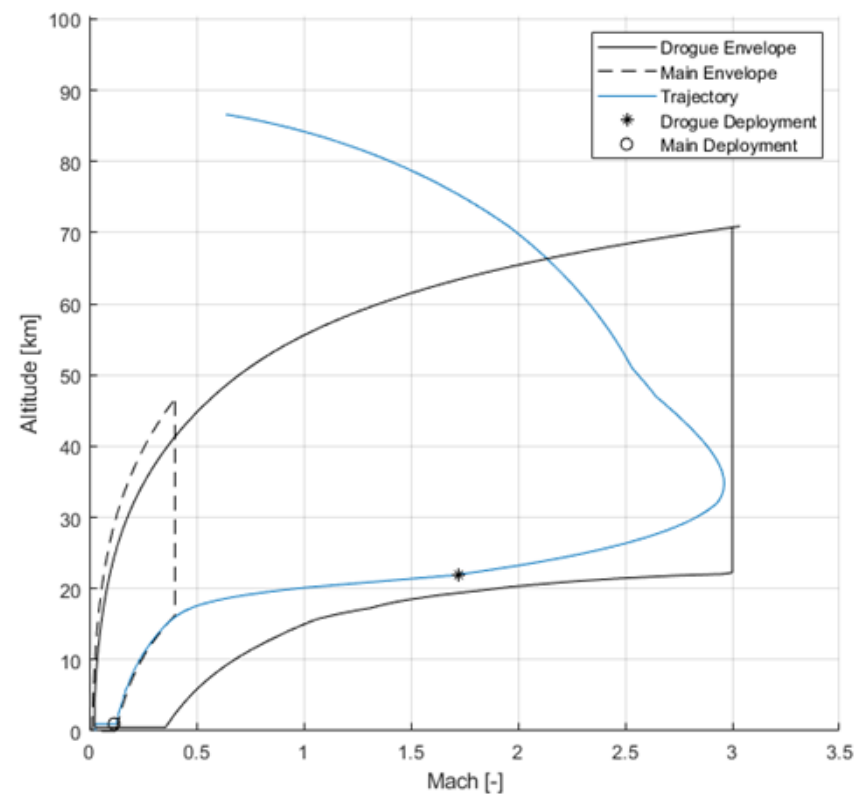

Figure 3 Flight Envelope of the SPEAR Flight 


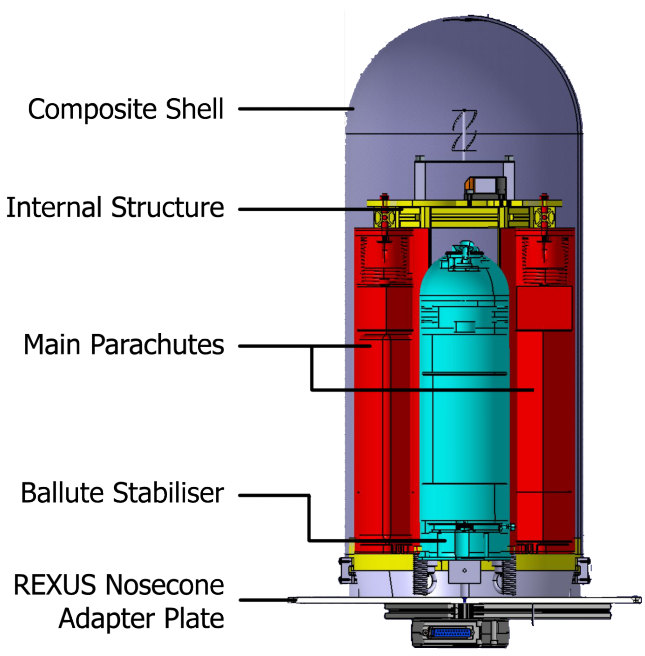

Figure 4 SPEAR vehicle - front view

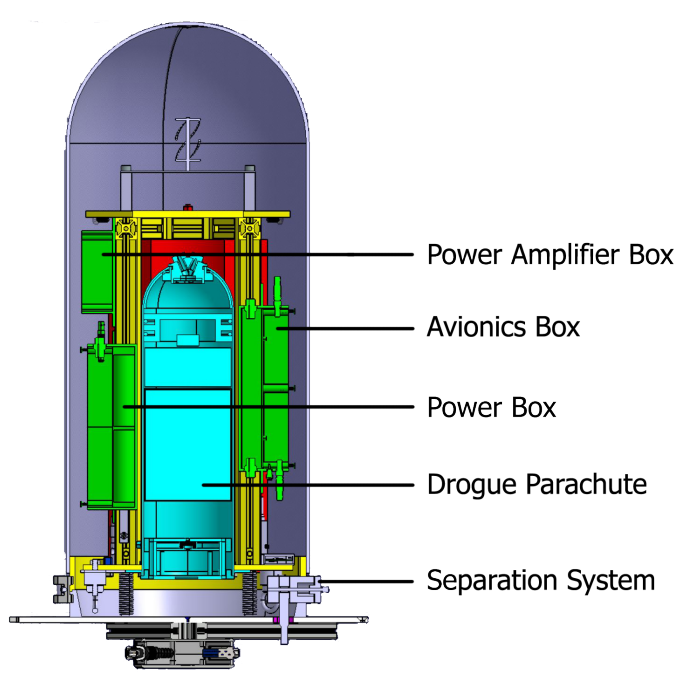

Figure 5 SPEAR vehicle - side view

As the vehicle was now stabilised, the available volume could be increased by adjusting the shape of the shell from being conical to cylindrical with a dome.

\section{B. Parachutes}

A total of six parachutes are required for the mission, and thus have to fit inside the vehicle, which in its turn should not conflict with the internals of the REXUS nose cone. These six parachutes consist of the stabilizing ballute, one Hemisflo ribbon drogue parachute and two main parachutes with one pilot chute each. The drogue parachute is connected to the main structure via three load cells. The two main parachutes are used to decelerate the vehicle to a safe landing velocity. Disk-Gap-Band parachutes are chosen as main parachutes as these have proven to be very stable during wind tunnel tests. This type is used to land the Stratos nose cone as well, for which SPEAR can provide useful parachute flight data. The main parachutes are attached to the main internal structure at the bottom of the main parachute canisters.

The drogue parachute is deployed using a hot gas deployment device (HGDD). The system works by igniting 0.5 grams of nitrocellulose, generating a rapidly increasing amount of gas in a confined volume, generating a pressure of 36 bar. The gas pushes the parachute and the sabot, shearing off a set of nylon bolts that keep the system closed [6]. The HGDD is used for the drogue deployment since it can deploy a parachute with a high velocity of $25 \mathrm{~m} / \mathrm{s}$, decreasing the chance of entanglement between the drogue parachute and the test vehicle. One of the main challenges encountered during the HGDD design was to figure out a suitable amount of nitrocellulose. Not using an adequate amount of nitrocellulose will not shear off the set of nylon bolts and eject the parachute with a sufficient velocity, whereas using too much will generate too much pressure that cannot be taken by the canister, leading to structural failure. 
Furthermore, as the drogue parachute is deployed around $25 \mathrm{~km}$, the HGDD has to function in low ambient pressures and air density. Pyrotechnic actuation in low air density is difficult, which is why the entire pyrotechnic section is sealed. Despite the seal, ignition in near vacuum is being thoroughly tested for redundancy.

A simple spring system is used to deploy the main parachutes and stabiliser. This system works by compressing a spring and keeping it in place using a wire. The wires are cut using wire cutters which releases the springs, ejecting the parachutes out of the canisters [6].

Most of the mechanisms inside SPEAR are triggered using Cypress wire cutters. These are lighter solutions than servoactuators and are very reliable as they are bought commercially off-the-shelf. Three sets of two wire cutters are used to trigger the deployment of the stabilisation parachute and both main parachutes. A set of two is used for redundancy reasons.

\section{Separation system}

The separation system holding SPEAR during the ascent which releases the vehicle on command was part of the design as well. As SPEAR has to cope with the qualification level vibrational loads up to $12 \mathrm{~g}$ RMS, it requires a strong and stiff separation system [7]. The selection of this system was challenging as there was a large variety of design options and changing requirements which made it difficult to perform a trade-off. For all hold down and release mechanisms, springs were chosen as ejection system.

The simplest hold down and release system was determined to be one where the vehicle is bolted down on REXUS and the bolts are disintegrated upon actuation. This can for instance be done using explosive bolts, explosive nuts, or Frangibolts ${ }^{\circledR}$. The main advantage of the latter system is that it can be reused and does not use pyrotechnics which increases testability and safety [8]. Unfortunately, these parts are expensive and procuring them was not possible for the SPEAR project. Another concept, used by the REXUS 25/26 BESPIN experiment [9], was considered as separation system as well. Here three tensioned steel cables hold down the experiment in the longitudinal axis supported by columns which prevent lateral movement. TRW Pyro cutters cut the steel cables and springs eject the experiment. For the SPEAR mission this design would need $3 \mathrm{~mm}$ thick steel cables, which are not possible to cut with the TRW cutters. Aside this there were doubts on the repeatability of assembly, as the pretention in these cables is very difficult to determine.

The last design option, a clamp band, was selected, see Figure 6. This design originally did not score best in the trade-off, due to a relative high mass and production effort. As there is more experience within DARE with this system [10] and it has a high stiffness, vibration resistance and reliability there is a high confidence in its success. The system consists of two half bands, connected by an actuation and tensioning mechanism. The actuation is done by cutting an M3 bolt with a Cypres wire cutter®.

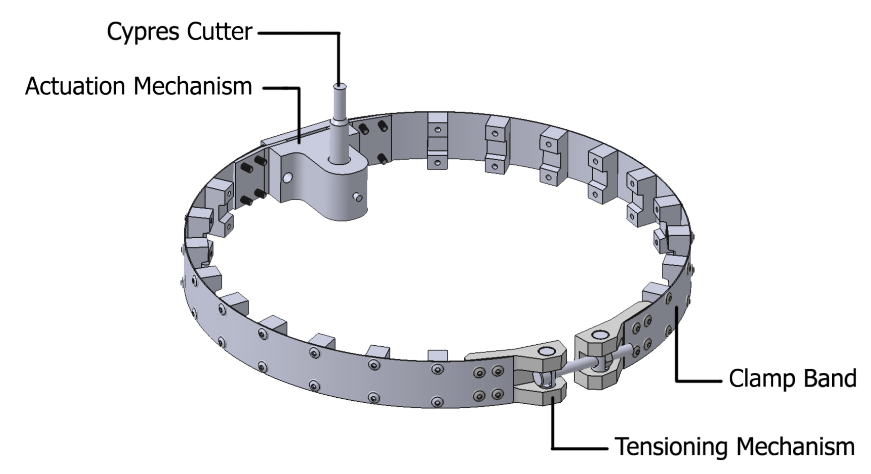

Figure 6 Separation mechanism - clamp band

\section{ELECTRONICS DESIGN}

The SPEAR electronics system contains three processing units and is responsible for actuation, recording flight and sensor data, handling video inputs, and telemetry. The three processing units are stored in two compartments in the SPEAR structure: the power subsystem container and the avionics subsystem container, see Figure 5.

The power subsystem container holds the lithium-ion batteries used to power the entire electronics system as well as the battery management system (BMS) processor. This processor controls the battery charging process, distributes and monitors the power throughout the electronics system and measures the environmental conditions inside the power subsystem container.

The avionics subsystem container houses two processors: the supervisor (SUP) processor and the Raspberry Pi Compute Model 3 (RPI) processor. The SUP processor controls actuation of pyrotechnical devices and handles the interface between SPEAR and the REXUS Service Module. The SUP processor also handles data storage in on-board black boxes as well as the retrieval subsystem, which includes a GPS module, Iridium modem and a VHF beacon for locating purposes.

The RPI processor is used for video processing and handling the high data-rate telemetry downlink. This downlink is achieved through an on-board software defined radio along with a power amplifier. Aside from telemetry handling the RPI processor also handles and stores the sensor data of the sensors used in SPEAR, including a heat flux sensor and load cells.

The use of a high data-rate telemetry downlink allows for live digital video streaming and uncompressed live data output, effectively providing the SPEAR team with data during flight through a telemetry receiver in the SPEAR electronics ground station setup. Part of this data can be used to monitor and predict the trajectory of the free-falling unit(FFU) in case the retrieval subsystem fails to provide the location of touchdown. Aside from retrieval purposes this direct data stream is captured directly by the ground station and can be used for post processing purposes. It therefore provides the SPEAR team with a great deal of data in case of unsuccessful retrieval of the vehicle. 
The data provided by the SPEAR electronics system will be essential for validating calculations on parachute, structural and thermal design.

\section{OUTLOOK}

Within the REXUS program, multiple experiments have been performed in the re-entry research area [11]. However, SPEAR is the first mission aiming to flight test a parachute recovery system. It could be considered to continue parachute research with new student missions that participate in the REXUS/BEXUS program. As can be seen in the SPEAR envelope, supersonic velocities can be obtained with a test vehicle. Testing a larger ballute stabiliser or the Disk-GapBand main parachutes supersonically are interesting subjects for future missions. These test vehicles should accommodate for the new requirements of these missions.

In the beginning of the SPEAR project, the location of the experiment within the REXUS rocket was still unsure, and multiple options were considered. These different configurations could be considered for future parachute research in the REXUS program.

The REXUS rocket offers three payload bays: two modules and one spot within the ejectable nose cone, see Figure 7.

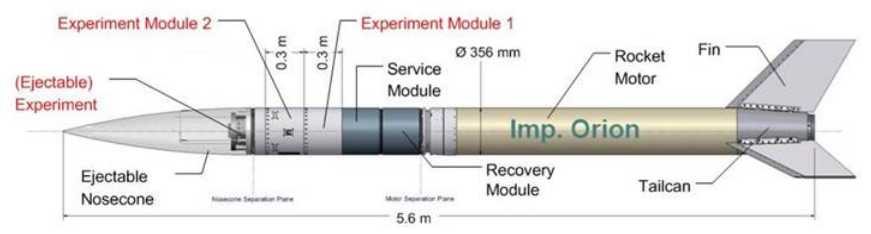

Figure 7 The REXUS Sounding Rocket [7]

An FFU can be deployed from all these locations. The module however has restrictions on the maximum size of a cut-out in the structure to maintain structural integrity, which limits the maximum size of an FFU [7]. This could be considered a feasible option when the experiment and vehicle are scaled down in complexity and size significantly. It would be recommended to only include one parachute, the test article, in this case. As the weight distribution of this FFU can lie more towards the dome end of the vehicle, it can be designed as such that it is inherently stable during descent.

Another possibility is to integrate the experiment in the REXUS nose cone. This has been done in some REXUS experiments such as Aquasonic [12]. This implementation removes the design of a main outer structure and separation system from the team's workload as the REXUS nose cone and nose cone ejection system are used for this. It also increases the area and volume that one can work with immensely. It does however require intense collaboration with REXUS as there are much more interfaces with the rocket compared with using the nose cone adapter plate as the single physical interface.
Lastly, one could opt to apply for the unconventional option of recovering the REXUS engine section. An experiment module could be placed between the yoyo de-spin and REXUS recovery module. This does have the downside of a large entanglement risk with the fins, and that the orientation of the engine under the parachute has to be switched. This is alike the Aether mission by DARE, and radial deployment should be considered [6].

\section{CONCLUSION}

The SPEAR mission provides the Parachute Research Group with a vehicle capable of fulfilling the need of supersonic parachute testing. The combination of IMU, load cells and cameras can provide a full overview of the supersonic capabilities of the LEAPS Hemisflo drogue parachute. The addition of a heat flux sensor to the sensor suite also allows for verification of the in-house developed simulation tools ParSim and TumSim. Based on first simulations, the vehicle is capable of reaching the velocity conditions required. However, further sensitivity analysis will be performed to ensure mission success.

Finally, it can be concluded that supersonic parachute testing is possible on board the REXUS sounding rocket and within student capabilities and experience.

\section{REFERENCES}

[1] Menting, E. et al. (2019). Evolution and evaluation of the DARE Large Envelope Advanced Parachute System, FAR, Capitolo, Italy , 2019 [unpublished].

[2] Lingard, J.S. (2017). Supersonic Parachute Testing Using a MAXUS Sounding Rocket Piggy-Back Payload, AIAA, Indianapolis, USA.

[3] Knacke, T. W. (1992). Parachute recovery systems: design manual. Santa Barbara, CA: Para Pub.

[4] Pepermans, L. et al. (2019). Trajectory simulations and sensitivity for the SPEAR parachute test vehicle, IAC, Washington, USA, 2019 [unpublished]

[5] Pepermans, L. et al. (2018). Flight Simulations of the Stratos III Parachute Recovery System, IAC, Bremen, Germany, 2018

[6] Pepermans, L. et al. (2019). Comparison of various parachute deployment systemsfor sounding rockets, EUCASS, Madrid, Spain, 2019.

[7] REXUS/BEXUS, EUROLAUNCH. (2018). REXUS user manual V7.16, retrieved from http://rexusbexus.net/rexus/rexus-user-manual/

[8] TiNi Aerospace, INC. (2019), Frangibolt. Retrieved from https://tiniaerospace.com/products/space-frangibolt/

[9] BeSpin. (2019). REXUS - BESPIN experiment. Retrieved from https://www.rexus-bespin.com/start

[10] DARE. (2019) Stratos IV structural design, retrieved from https://dare.tudelft.nl/stratos/.

[11] REXUS/BEXUS. (2019). REXUS/BEXUS experiments. Retrieved from http://rexusbexus.net/experiments/technology-demonstrators/re-entrysystems/

[12] Aquasonic. (2019). REXUS - Aquasonic experiment. Retrieved from http://rexusbexus.net/experiments/technology-demonstrators/othertechnologies/ 